\title{
EDITORIAL \\ Making the diagnosis of cyclic Cushing's syndrome: a position statement from the topic editors
}

\author{
John D. Carmichael, MD, ${ }^{1}$ Gabriel Zada, MD, ${ }^{1}$ and Warren R. Selman, MD² \\ 1 USC Pituitary Disorders Center, Keck School of Medicine of the University of Southern California, Los Angeles, California; and \\ 2Department of Neurological Surgery, Case Medical Center, Cleveland, Ohio
}

A MINORITY of patients with Cushing's syndrome (CS) exhibit periods of excess cortisol secretion interspersed with periods of normal cortisol secretion..$^{10}$ This phenomenon has been referred to as cyclic, intermittent, or periodic CS in the literature, and affected patients comprise a rare subset of CS patients, although some reports have estimated the prevalence to be at least $15 \%$. The diagnosis of cyclic CS can be difficult to make given the variations in clinical presentation, the unpredictability of cyclic secretion, and the lack of uniformity in etiology. As with classic CS, the etiology of the excess cortisol production can be adrenocorticotropic hormone (ACTH) dependent (from either a pituitary adenoma or an ectopic source) or ACTH independent. ${ }^{7}$ Patients can present with varying degrees of the cushingoid phenotype, but the disease is most often considered when signs and symptoms of cortisol excess are present and biochemical testing is normal. Criteria for the diagnosis of cyclic CS include three peaks and two troughs of cortisol production, although the phenomenon of increase and decline in cortisol production (albeit to a lesser degree) is seen in many patients undergoing workup for cortisol excess. ${ }^{2}$

The diagnosis of CS is often challenging, even without considering the phenomenon of cycling cortisol production. ${ }^{9}$ Cushing's syndrome is a rare disease, and its commonly associated signs and symptoms (for example, obesity, hypertension, and diabetes mellitus) are also prevalent in patients without pathophysiological hypercortisolemia. Several pitfalls frequently encountered during the workup of cortisol excess include cortisol elevations associated with so-called pseudo-Cushing's states (alcohol withdrawal, depression, eating disorders), medications that may affect testing cortisol secretion (through either direct effects on endogenous secretion, affecting binding protein concentration, or laboratory methods applied to measuring cortisol), and the inherent accuracy of the tests commonly used in diagnosing cortisol excess in which false-negatives and false-positives are commonly encountered..$^{5,6,8}$

Cyclic CS adds another dimension of complexity and presents its own set of challenges when attempting to diagnose suspected CS. ${ }^{11}$ Obvious challenges arise when diagnosing a patient during periods of biochemical normalcy, but there have also been paradoxical results to dexamethasone testing that can complicate the diagnosis beyond simply finding normal results. ${ }^{3}$ Similarly, advancing the sequence of testing to the differential diagnosis stage (testing for ACTH dependence and further testing for localization with inferior petrosal sinus sampling [IPSS]) can lead to misclassification when testing is performed during a trough phase.

Of the utmost concern to patient and physician is the central question of whether or not the patient being examined truly has CS. The syndrome's diagnosis is best made using a stepwise Bayesian approach wherein the probability of having CS is related to the pretest probability of disease. ${ }^{4}$ The likelihood of having the disease changes based on the results of successive tests, and the final determination rests on the cumulative evidence gathered during the investigation. Simply put, positive test results increase the likelihood of having the disease, and negative test results lower the likelihood of having the disease. When the pretest probability of having CS is high, an accumulation of negative testing is required to lower the likelihood of having the disease down to a level at which CS can be ruled out. Applying this idea to cyclic CS, several tests are required (often over a significant span of time) to best 
determine if the disease is truly present or absent. When the diagnosis of cyclic CS is being considered, reliance on late-night salivary cortisol measurements or 24-hour collections of urinary free cortisol is recommended to best assess patients, and this should be done at a time when the pretest probability is highest-a period during which the patient feels most symptomatic is ideal. It is difficult to determine the duration of follow-up required to rule out the disease, since the interval between periods of cortisol excess has often been noted to be many years. ${ }^{1}$ Regardless, the workup of cyclic CS should only be undertaken when suspicion remains high, and not in all cases of repeatedly negative testing. Furthermore, when hypercortisolemia is not confirmed with repeated testing, more advanced diagnostic testing, including dexamethasone suppression/ corticotropin-releasing hormone (Dex-CRH) testing, serum ACTH measurement, and IPSS, should not be performed, as these tests have not been shown to elucidate the diagnosis and may lead to unnecessary treatment and costs. Similarly, any treatment, whether medical or surgical, should be reserved for patients whose likelihood of cyclic CS is high, and not when testing is equivocal.

http://thejns.org/doi/abs/10.3171/2014.11.FOCUS14778

\section{References}

1. Alexandraki KI, Kaltsas GA, Isidori AM, Akker SA, Drake WM, Chew SL, et al: The prevalence and characteristic features of cyclicity and variability in Cushing's disease. Eur J Endocrinol 160:1011-1018, 2009

2. Brown RD, Van Loon GR, Orth DN, Liddle GW: Cushing's disease with periodic hormonogenesis: one explanation for paradoxical response to dexamethasone. J Clin Endocrinol Metab 36:445-451, 1973

3. Checchi S, Brilli L, Guarino E, Ciuoli C, Di Cairano G, Mazzucato P, et al: Cyclic Cushing's disease with paradoxical response to dexamethasone. J Endocrinol Invest 28:741-745, 2005

4. Cipoli DE, Martinez EZ, Castro M, Moreira AC: Clinical judgment to estimate pretest probability in the diagnosis of Cushing's syndrome under a Bayesian perspective. Arq Bras Endocrinol Metabol 56:633-637, 2012

5. Elamin MB, Murad MH, Mullan R, Erickson D, Harris K, Nadeem S, et al: Accuracy of diagnostic tests for Cushing's syndrome: a systematic review and metaanalyses. J Clin Endocrinol Metab 93:1553-1562, 2008

6. Findling JW, Raff H: Cushing's Syndrome: important issues in diagnosis and management. J Clin Endocrinol Metab 91:3746-3753, 2006

7. Meinardi JR, Wolffenbuttel BH, Dullaart RP: Cyclic Cushing's syndrome: a clinical challenge. Eur J Endocrinol 157:245-254, 2007

8. Newell-Price J, Trainer P, Besser M, Grossman A: The diagnosis and differential diagnosis of Cushing's syndrome and pseudo-Cushing's states. Endocr Rev 19:647-672, 1998

9. Nieman LK, Biller BM, Findling JW, Newell-Price J, Savage MO, Stewart PM, et al: The diagnosis of Cushing's syndrome: an Endocrine Society Clinical Practice Guideline. J Clin Endocrinol Metab 93:1526-1540, 2008

10. Velez DA, Mayberg MR, Ludlam WH: Cyclic Cushing syndrome: definitions and treatment implications. Neurosurg Focus 23(3):E4, 2007

11. Yasuda K: Cyclic Cushing's disease: pitfalls in the diagnosis and problems with the pathogenesis. Intern Med 35:169_ 170,1996 